\title{
Internalisasi Nilai Tri-Silas melalui Pembelajaran Tari Anak Berbasis Budaya Lokal
}

\author{
Dedi Rosala1 ${ }^{1}$ Juju Masunah ${ }^{2}$, Tati Narawati ${ }^{3}$, Tri Karyono ${ }^{4}$, Ayo Sunaryo ${ }^{5 凶}$ \\ Pendidikan Seni, Universitas Pendidikan Indonesia \\ DOI: $10.31004 /$ obsesi.v5i2.1087
}

\begin{abstract}
Abstrak
Pembelajaran tari anak yang berbasis pada kearifan lokal di sekolah sangat penting untuk meningkatkan pendidikan karakter dengan mengiinternalisasi nilai- nilai Tri-Silas (silih asah, silih asih, silih asuh) pada diri anak. Tujuan penelitian ini adalah untuk menganalisis efektifitas pembelajaran dan nilai-nilai Tri-Silas yang terdapat pada Tari Anak yang dijadikan sebagai bahan ajar di sekolah. Data kualitatif diperoleh dengan cara mengobservasi dari 52 siswa serta melakukan wawancara yang mendalam pada 1 orang guru mengenai pembelajaran tari anak yang berbasis pada budaya lokal sebagai data kualitatif. Data kuantitatif untuk mengetahui efektifitas pembelajaran dan dianalisis dengan menggunakan Uji statistik yang digunakan dalam penelitian ini adalah uji statistik non parametrik atas dasar Uji efektivitas menggunakan Uji Wilcoxon. Hasil penelitian ini adalah terinternalisasinya nilai-nilai Tri-Silas pada anak melalui pembelajaran tari anak dengan cara belajar secara kelompok, bergotong royong, bersemangat, jujur, ikhlas, saling membantu dan berempati. Mengenalkan tari anak pada siswa merupakan cara yang efektif dalam menginternalisasikan nilai-nilai Tri-Silas.
\end{abstract}

Kata Kunci: tari anak; internalisasi; tri-silas.

\begin{abstract}
Learning dance for children based on local wisdom in schools is very important to improve character education by internalizing the values of Tri-Silas (silih asah, silih asih, silih asuh) in children. The purpose of this study was to analyze the effectiveness of learning and the Tri-Silas values contained in the Children's Dance which were used as teaching materials in schools. Qualitative data were obtained by observing 52 students and conducting in-depth interviews with 1 teacher regarding children's dance lessons based on local culture as qualitative data. Quantitative data to determine the effectiveness of learning and analyzed using statistical tests used in this study is a non-parametric statistical test, effectiveness of using the Wilcoxon Test. The result of this research is the internalization of the Tri-Silas values in children through children's dance learning by learning in groups, mutual cooperation, enthusiasm, honesty, sincerity, mutual assistance and empathy. Introducing children's dance to students is an effective way to internalize the Tri-Silas values.
\end{abstract}

Keywords: child dance; internalisation; tri-silas.

Copyright (c) 2021 Dedi Rosala, Juju Masunah, Tati Narawati, Tri Karyono, Ayo Sunaryo

$\triangle$ Corresponding author:

Email Address : ayosekolah@upi.edu (Bandung, Jawa Barat, Indonesia)

Received 24 January 2021, Accepted 7 February 2021, Published 10 February 2021 


\section{PENDAHULUAN}

Nilai adalah suatu penghargaan atau kualitas terhadap sesuatu hal yang dapat menjadi dasar penentu tingkah laku seseorang. Sesuatu itu dianggap bernilai bagi seseorang karena sesuatu itu menyenangkan (pleasant), memuaskan (satisfying), menarik (interest), berguna (useful), menguntungkan (profitable) atau merupakan satu keyakinan (bilief) (Daroeso, 1988, dalam Kuswarsantyo, 2012, hlm. 19). Dari pernyataan tersebut nilai merupakan pondasi bagi manusia dalam menempuh kehidupannya. Tentu saja, nilai yang baik harus mulai tertanam dalam diri anak sejak usia belia agar saatnya dewasa berperilaku dalam koridor nilai-nilai yang baik. Selanjutnya, Kuswarsantyo (2012, hlm. 20) menjelaskan ada kaitan yang erat antara yang bernilai dengan yang baik. Nilai pada dasarnya berhubungan dengan kebaikan yang terdapat pada inti sesuatu hal. Dengan demikian nilai itu merupakan kadar relasi positif antara sesuatu hal dengan orang tertentu dan nilai dapat saling berkaitan membentuk suatu sistem dan antara satu dengan lain koheren serta mempengaruhi segi kehidupan manusia. Pendapat tersebut menjelaskan bahwa nilai merupakan sistem yang selalu berkaitan secara erat dalam kehidupan manusia. Konsep nilai pada masyarakat sebenarnya sudah ada sejak dahulu yang selalu menjadi pijakan bagi manusia sezamannya, bahkan konsep nilai tersebut masih dipakai pada manusia setelahnya atau pada zaman sekarang ini (Sunaryo, 2020a).

Jika melihat sejarah Sunda, pada zaman kerajaan Sunda yang rajanya adalah Prabu Siliwangi yang namanya pekat bernuansa mitos dan memerintah kerajaan Pajajaran 1482-1521 Masehi. Masyarakat Sunda sangat menghormati dan menyakralkannya (Sundalana, 2006, hlm. 43). Kalimat silih asih, silih asah, silih asuh tertera jelas dalam Kitab Sanghyang Siksa Kandang Karesian yang ditulis di atas tujuh helai daun lontar (Danasasmita, 1987, hlm. 42). Naskah Sanghyang Siksakandang Karesian Kropak 630 berasal dari koleksi pemberian Raden Saleh kepada Bataviaasch Genootschap van Kunsten en Weteschapen, yaitu lembaga kebudayaan yang didirikan di Batavia pada tahun 1778, sedangkan naskah Sanghyang Siksa Kandang Karesian Kropak 624 berasal dari koleksi pemberian Bupati Bandung Wiranatakusumah IV tahun 18461874 (Krom, 1914 dalam Wartini, dkk, 2010 dalam Nurwansah, 2013, hlm. 151). Naskah Sanghyang Siksakandang Karesian Kropak 630 ditulis dengan aksara Buda/Gunung menggunakan tinta, pada bahan nipah. Lempiran-lempiran tersebut disatukan dengan benang kasur warna putih yang dimasukkan pada lubang kecil di bagian tengah naskah. Pengapit terbuat daru dua bilah bambu tutul (Nurwansah, 2013, hlm. 153). Dari asal-usul inilah, nilai-nilai yang terdapat dalam konsep silih asih, silih asah, silih asuh (Tri-Silas) digali dan dijadikan landasan nilai dalam kehidupan bermasyarakat, termasuk dalam bidang pendidikan yang berbasis pada kearifan lokal. Di bawah ini adalah penjabaran nilai Tri-Silas yang disarikan dari teorinya Suryalaga (2010).

Tabel 1. Nilai-Nilai Tri-Silas

\begin{tabular}{llll}
\hline \multicolumn{1}{c}{ SILH ASIH } & \multicolumn{1}{c}{ SILIH ASAH } & \multicolumn{1}{c}{ SILIH ASUH } \\
\hline 1. Asih karena adanya & 1. Asah berarti bersemangat & 1. Asuh adalah menghargai \\
empati & 2. Asah yaitu adanya kejujuran & 2. Asuh adalah keikhlasan hati \\
2. Asih adalah kemampuan & 3. Asah adalah kreativitas & 3. Asuh adalah kesediaan untuk \\
berdisiplin & 4. Asah adalah kemampuan & berkorban \\
3. Asih meminta kesabaran & berkomunikasi & 4. Asuh adalah kebeningan hati \\
4. Asih adalah pengorbanan & 5. Asah adalah kemampuan & 5. Asuh yaitu kebersamaan \\
5. Asih adalah penghormatan & bersinergi & \\
& &
\end{tabular}

Pendidikan berbasis kearifan lokal memiliki prinsip Tri-Silas yang bertujuan menghasilkan Jelema masagi yang berkarakter cageur, bageur, bener, pinter, tur singer. Di belahan dunia lain, prinsip ini lazim disebut pendekatan kooperatif, yang berpandangan bahwa manusia adalah makhluk sosial yang satu sama lain saling membutuhkan karenanya 
harus ada interaksi yang saling menyayangi atau berkelompok (silih asih). Sebagai makhluk sosial, manusia memiliki perbedaan sehingga dapat saling mencerdaskan atau berpikir (silih asah). Pembelajaran kooperatif secara sadar menciptakan interaksi belajar-mengajar yang saling berbagi atau sharing (silih asuh) Nurhadi dan Senduk (dalam Sudaryat, 2016, hlm. 13).

Makna kearifan lokal yang terkandung dalam Tri-Silas ternyata sarat dengan nilai kemanusiaan yang universal. Silih asih dimaknai sebagai mengasihi dengan segenap kebeningan hati, silih asah bermakna saling mencerdaskan kualitas kemanusiaan, sedangkan silih asuh adalah kehidupan yang penuh harmoni (Suryalaga, 2003, hlm. 90-106). Yargon silih asih, silih asah, dan silih asuh merupakan sistem berinteraksi dalam masyarakat yang mengandung kebersamaan dalam kemitraan dan keterlibatan yang bertanggung jawab. Sikap moral ini harus dimiliki oleh seorang pendidik yang ideal. Karena seorang pendidik yang ideal harus mampu mensejahterakan peserta didik atau bawahan dalam kehidupannya (Sunaryo, 2020).

Kata "silih" menjadi kunci pembuka untuk mendalami kosmologi atau tatanan ontologis dalam kebudayaan Sunda. Kata ini sendiri dalam leksikon Sunda merujuk pada kata kerja penyambung yang menyiratkan nuansa "berbalas", "timbal balik", atau "mengambil alih". Kemudian dalam bahasa Indonesia, kata ini diterjemahkan sebagai "saling" dan "ganti/menggantikan/digantikan". Terjemahan konotatif tersebut perlu diperdalam dengan nuansa filosofis. Nuansa filosofis ini digali melalui interpretasi atas implikasi dari penggunaan kata ini (Djunatan, 2011, hlm. 119).

Silih asih atau rasa saling menyayangi juga tentulah harus menjadi budaya yang mendarah-daging di kehidupan masyarakat kita karena ini merupakan kunci dari terwujudnya sebuah masyarakat yang bersatu dengan kokoh. Menumbuh-kembangkan budaya silih asih mestilah dilakukan dengan membangun kesadaran akan arti kesatuan dan kesamaan nilai-nilai kemanusiaan. Kesadaran bahwa manusia tidak dapat hidup tanpa manusia lainnya, kesadaran bahwa setiap manusia terlahir dengan kebutuhan dan kecenderungan yang sama, kesadaran bahwa kedamaian hanya dapat terwujud ketika manusia bersedia untuk saling bersaudara, kesadaran bahwa bermusuhan dan berpecah belah hanya akan membawa manusia kepada kesengsaraan dan kehancuran, dan berbagai kesadaran serupa lainnya harus tumbuh agar sikap silih asih ini dapat menajadi sikap yang mewarnai keseharian kehidupan bermayarakat kita. Sikap hidup yang demikian ini dapat diwujudkan maka sungguhlah kita benar-benar akan menjadi masyarakat yang sangat-sangat kuat. Silih asih merupakan tingkah laku yang memperlihatkan rasa kasih sayang yang tulus sehingga terwujud kebahagiaan. Asih menuntut kejujuran, dedikasi, kedisiplinan, kesabaran, ekspresi diri, dan rasa keindahan. Substansi silih asih mengacu pada kualitas intrinsik yang berada dalam batiniah seseorang. Bila rasa asih telah bersemayam dalam batiniah setiap pendidik, maka hubungan sosial kelas pun akan selalu dilandasi dengan getaran keindahan nilai manusiawi yang selaras dan harmonis, yang bermuara pada kebahagiaan bersama sebagaimana tertuang dalam naskah kuno Sanghyang Siksa Kandang Karesian (1518 M) yang berbunyi "Ngertakeun bumi lamba" yakni menyejahterakan alam dunia (Sudaryat, 2016, 14).

Silih asah atau budaya saling memintarkan haruslah tumbuh dengan kuat dalam kehidupan bermasyarakat kita. Terwujudnya masyarakat yang cerdas merupakan sebuah syarat terbentuknya tatanan masyarakat yang kuat. Silih asah dalam praktek kehidupan keseharian kita dilakukan dengan saling ingat mengingatkan, saling mengajarkan dan saling berbagi ilmu dan pengetahuan yang berguna satu sama lainnya. Pendidikan dan pengajaran tidak saja harus dilakukan di sekolah-sekolah atau di fakultas-fakultas melainkan juga di setiap ruang dan segala aspek di kehidupan bermasyarakat kita. Budaya belajar harus berlangsung dalam berbagai kegiatan keseharian kita. Pengetahuan haruslah dengan bebas bergerak menjangkau setiap orang melalui buku-buku, melalui media cetak, internet, radio, televisi dan juga dari mulut ke mulut. Silih asah adalah saling mencerdaskan, saling menambah ilmu pengetahuan, memperluas wawasan dan pengalaman lahir batin untuk peningkatan kualitas kemanusiaan dalam segala aspeknya, baik pada tataran kognisi, afeksi, 
spiritual, maupun psikomotor. Silih asah bertujuan mempersiapkan SDM agar mampu mengatasi tantangan dan masalah yang dihadapinya. Hal ini sangat penting bagi seorang pendidik agar terjalin komunikasi dan adanya pentransferan yang baik dan lancar antara pendidik dan peserta didik. Silih asah merupakan proses aktivitas antara dua pihak, ada yang berperan sebagai pemberi dan penerima pengetahuan. Asah berarti memiliki visi dan misi, pengendalian diri, alat ukur (barometer) di dalam mencapai tujuan, menuntut adanya kesabaran, memerlukan keterbukaan, memiliki sistem keteraturan, kemampuan mengelola, inovatif, proaktif, pandai berkomunikasi dan bersinergi (Sudaryat, 2016, hlm. 15).

Silih asuh atau sikap saling memelihara juga dapatlah dikatakan merupakan sikap yang hanya dapat mengakar dan menjadi budaya keseharian masyarakat jika kesadaran akan kesatuan dan kesamaan nilai-nilai kemanusiaan tadi telah terbentuk. Kesadaran akan ini memanglah merupakan hal yang fundamental. Kita mesti dapat menghilangkan batas-batas yang telah menyebabkan kita terkotak-kotak dan terpecah-belah. Perbedaan-perbedaan seperti agama, suku, ras atau kelompok tidaklah boleh membuat kita menjadi terpisah, terpecah dan saling memusuhi. Umat manusia itu ditakdirkan untuk bersaudara. Di dalam persaudaraan itulah umat manusia dapat menemukan kedamaian dan kesempurnaannya. Saling memangsa, saling menganiaya dan saling memakan bukanlah bagian dari kemanusiaan. Itu adalah isme-isme kebinatangan yang tidak boleh ada dan menjadi bagian dalam kehidupan kita manusia. Setiap orang tanpa terkecuali haruslah disadarkan akan kemanusiaannya. Akan bagaimana menjalani hidup sebagai manusia. Dan ciri utama manusia dan kemanusiaannya adalah cinta kasih. Ketika seorang manusia menanggalkan cinta kasih dari dirinya maka saat itu juga ia telah kehilangan kemanusiaannya. Cinta kasih adalah penentu baik buruknya tumbuh kembang peradaban umat manusia. Silih asuh mengandung makna membimbing, menjaga, mengayomi, memperhatikan, mengarahkan, dan membina secara saksama dengan harapan agar selamat lahir batin dan bahagia di dunia maupun di akhirat. Dengan demikian, asuh dapat ditafsirkan sebagai kesederajatan, mampu menghargai, bersifat adil, bersifat satria, kebeningan hati, menuntut tanggung jawab dan kebersamaan (Sudaryat, 2016, hlm. 15).

Penelitian terhadap karya tari anak pada tahun 2011 dilakukan oleh Mirriam Giguere yang merupakan dosen di Departemen Seni Pertunjukan Universitas Drexel, Philadelphia. Pada penelitiannya ia menganalisis tiga jenis produk tari anak, yaitu produk tari anak diciptakan untuk anak-anak oleh orang dewasa, produk tari anak orang dewasa yang bekerja dengan anak, dan produk tari anak yang diciptakan oleh anak itu sendiri. Pada saat penelitiannya ia menganalisis pertunjukan resital studio dan kompetisi. Hampir anak-anak di seluruh Amerika terlibat dalam pertunjukan tari.

Ada tiga model umum untuk penciptaan tarian anak-anak: (Giguere, 2011, hlm. 84). Konsep penciptaan tari yang pertama adalah tari yang dibuat orang dewasa untuk konsumsi anak-anak (Children Dances Created for Children by Adults), tari yang buat anak dan orang dewasa, dan tari yang dibuat oleh anak itu sendiri (Children Dances Created with Children with Adults). Hal ini memungkinkan anak memasukkan beberapa masukan kreatif ke dalam karya tari yang dibuat bersama guru. Ini mengakui kesempatan siswa untuk berkontribusi pada pekerjaan yang mereka lakukan, dan bukan hanya merupakan instrument koreografer. Ini juga mengakui bahwa anak-anak memiliki kontribusi yang sangat berharga untuk melakukan pekerjaan tersebut. 


\section{METODOLOGI}

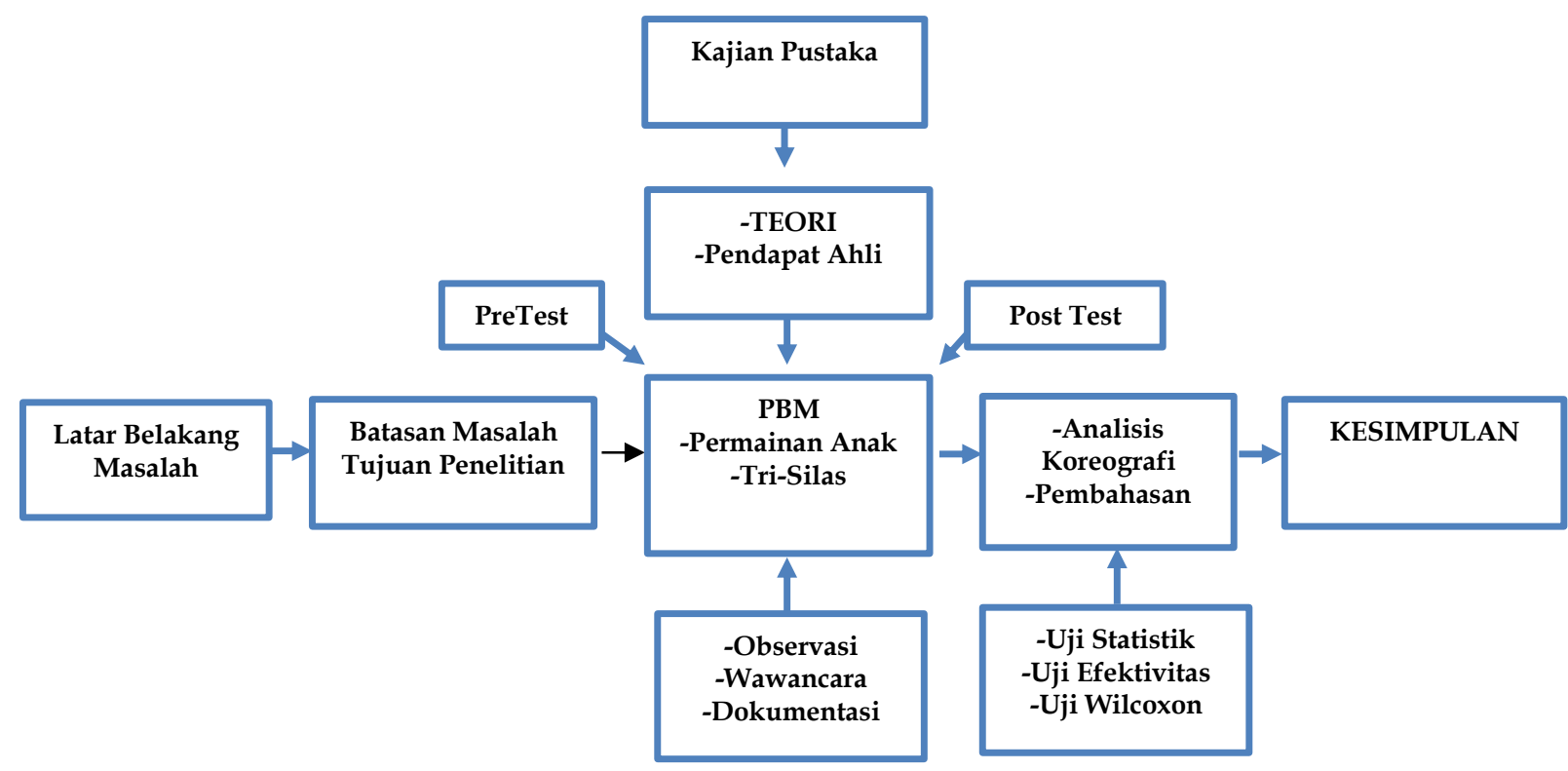

Bagan 1. Alur Metodologi Penelitian

Metodologi yang dipergunakan adalah metode kuantitatif dan kualitatif. Data kualitatif diambil dari observasi dan wawancara pada 1 orang guru dan siswa YAS (Yayasan Atikan Sunda) Bandung. Partisipan pada penelitian ini menggunakan 52 siswa dengan 19 orang laki-laki dan 23 siswa perempuan. Adapun partisipan 1 guru diobservasi dan diwawancarai secara mendalam untuk memeroleh data dalam mengembangkan pembelajaran dengan cara membantu siswa menciptakan tari anak yang berbasis pada budaya lokal dan materinya bersumber pada permainan anak yang ada di Jawa Barat, sebagai data kualitatif. Data kuantitatif untuk mengetahui efektifitas pembelajaran dan dianalisis dengan menggunakan Uji statistik yang digunakan dalam penelitian ini adalah uji statistik non parametrik, atas dasar Uji Normalitas yang menunjukan distribusi data yang tidak normal. Untuk mengetahui efektivitas antara pre-test dan post-test yang telah dilaksanakan dalam penerapan model ini, peneliti menggunakan Uji Wilcoxon, karena data termasuk pada non parametrik. Uji Wilcoxon digunakan sebagai alternatif dari uji paired sample $t$ test, jika data penelitian tidak berdistribusi normal. Adapun indikator penilaian sebagaimana pada tabel 2 ..

Tabel. 2 Indikator Penilaian

\begin{tabular}{clll}
\hline VARIABEL & INDIKATOR & \multicolumn{1}{c}{ SUB-INDIKATOR } & NO ITEM \\
\hline $\begin{array}{c}\text { Tri-Silas } \\
(\mathbf{X})\end{array}$ & Silih Asih & $\begin{array}{l}\text { empati,berdisiplin, kesabaran, pengorbanan, } \\
\text { penghormatan }\end{array}$ & $1,2,3,4,5$ \\
& Silih Asah & $\begin{array}{l}\text { Bersemangat, kejujuran, kreativitas, berkomunikasi, } \\
\text { bersinergi } \\
\text { Menghargai, keikhlasan hati, berkorban, } \\
\text { kebersamaan }\end{array}$ & $\mathbf{6 , 7 , 8 , 9}$ \\
& Silih Asuh & $10,11,12,13,14$ \\
\hline $\begin{array}{c}\text { Tari Anak } \\
(\mathrm{Y})\end{array}$ & Improvsasi & $\begin{array}{l}\text { Eksplorasi bentuk permainan anak, tema tari, } \\
\text { struktur dramatik } \\
\text { Eksplorasi gerak, desain lantai, aspek dasar tari } \\
\text { kelompok }\end{array}$ & $\mathbf{1 , 2 , 3} 4,5,6,7$ \\
& Eksplorasi & $\begin{array}{l}\text { Peduksi koreografi, pembentukan, penyajian } \\
\text { (forming) }\end{array}$ & $8,9,10$ \\
\hline
\end{tabular}




\section{HASIL DAN PEMBAHASAN}

Banyak pendidik tari menganjurkan penggunaan tari sebagai alat untuk belajar, terutama di sekolah (Giguere, 2006). Tari anak terdiri dari tari yang diciptakan oleh anak, tari anak diciptakan oleh orang dewasa bersama anak dan tari anak yang diciptakan oleh orang dewasa (Giguere, 2011). Pembelajaran tari anak sangat jarang dilakukan oleh guru-guru di sekolah. Kebanyakan guru seni mengajarkan tari dewasa untuk anak-anak. Padahal, tari untuk dewasa kadang-kadang tidak sesuai dengan kemampuan motorik dan psikologi anak (Sunaryo, Narawati, Masunah, \& Nugraheni, 2020). Tari anak yang dicicptakan oleh orang dewasa harus memperhatikan estetika tari dan psikologi anak agar karya tari anak menjadi bernilai dan terinternalisasi dalam diri anak (Sunaryo, 2020b).

Karakter adalah watak umum yang relatif mapan dari seseorang untuk melakukan hal-hal yang baik secara moral dan harus menjadi ciri khas seseorang (Davis, 2003). Pada pembelajaran tari pendidikan tidak lepas dari upaya pembentukan karakter anak selain produk tari (Malarsih \& Herlinah, 2014), karena kecenderungan remaja sekarang mempunyai karakter negatif karakter dan penurunan moral (Krakowiak \& Tsay-Vogel, 2013). Karakter yang diharapkan di Indonesia adalah anak-anak yang memiliki karakter bangsa (Kartadinata, 2010). Pendidikan berbasis karakter menjadi salah satu solusi untuk mengatasi permasalahan tersebut, pendidikan berbasis karakter pada anak melalui pembelajaran seni tari adalah efektif. Proses pembelajarannya dapat menanamkan nilai-nilai karakter seperti disiplin, jujur, tanggung jawab, religius, patriotisme, dan peduli lingkungan (Rakimahwati, 2014). Pembelajaran karakter pada anak bisa mencegah radikalisme (Yani \& Jazariyah, 2020). Adapun karakter yang terdapat pada permainan tradisi anak bisa mengembangkan aspek spikomotor, moral, nilai agama dan sosial (Noviati \& Giwangsa, 2018). pengajaran pendidikan karakter. Meski demikian, karakter pendidikan harus diintegrasikan dengan semua mata pelajaran untuk hasil yang lebih baik (Novianti, 2017).

Pembelajaran tari anak yang bersumber pada materi kearifan budaya lokal harus memperhatikan nilai- nilai yang ada di dalamnya agar nilai tersebut mempunyai karakter baik untuk anak didik. Pada penelitian ini, pembelajaran dilaksanakan secara bertahap dan sistematis. Adapun langkah-langkah yang digunakan guru dalam mengajarkan penciptaan tari anak bersama orang dewasa adalah sebagai berikut.

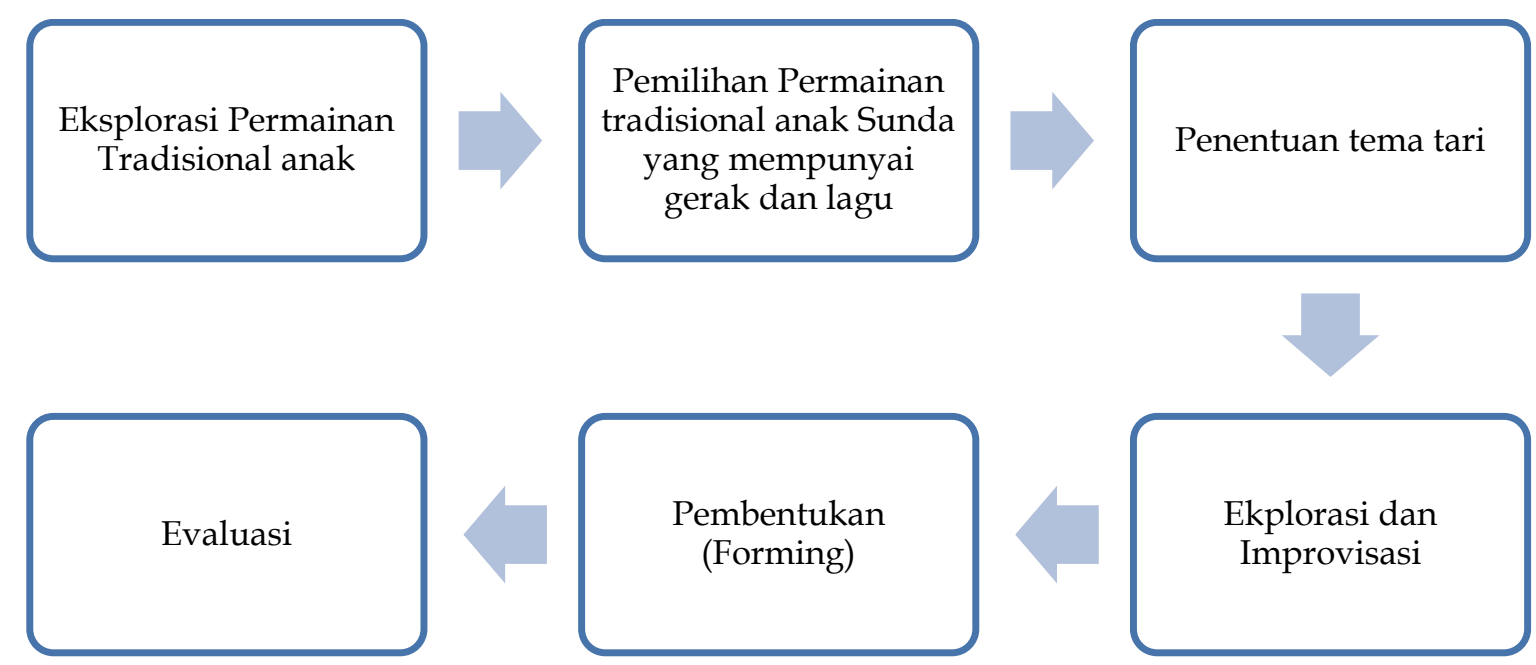

\section{Gambar 1. Langkah-langkah Penciptaan Tari Anak Berbasis Budaya Lokal}

Sintaks pembelajaran di atas merupakan sebuah metode untuk menciptakan tari anak yang berbasis pada budaya lokal. Penciptaan tari anak ini meliputi bebera tahap. Pertama adalah eksplorasi tentang bentuk-bentuk permainan tradisional anak dengan cara memperagakan gerak dan menyayikan lagunya Tahap dua adalah memilih bentuk-bentuk 
permainan anak mempunyai koreografi baku untuk dikembangkan. Tahap tiga adalah membuat tema tari dengan menggunakan alur ceritera dan struktur dramatik. Tahap empat adalah kegiatan improvisasi yaitu penjajagan awal tentang konsep koreografi dan eksplorasi yaitu pencarian gerak-gerak pengembangan darii koreografi yang telah ada. Tahap Lima adalah pembentukan atau reduksi koreografi menjadi koreografi baku pada tahap akhir. Tahap enam adalah analisa nilai-nilai Tri-Silas pada koreografi pembentukan tahap akhir dengan menganalisa setiap koreografi yang telah dibuat menggunakan pendekatan ilmu komposisi tari.

Pertemuan kesatu adalah tahap eksplorasi permainan tradisional anak, pada tahap ini siswa mampu mengeksplorasi bentuk-bentuk permainan anak dan memberikan pemahaman terhadap apresiasi bentuk-bentuk permainan anak yang disebut dengan kaulinan dan kakawihan dan nilai yang dikandungnya. Adapun materinya adalah pertunjukan kakawihan dan kaulinan, nilai Tri-Silas, perbedaan kakawihan dan kaulinan, kajian terhadap koreografi kakawihan dan kaulinan sebagai stimulus untuk memunculkan gagasan mencipta karya tari anak. Pertemuan ini lebih menekankan pada apresiasi melalui apresiasi tentang permainan anak, pada kegiatan apresiasi menggunakan media video dengan menampilkan video-video kakawihan dan kaulinan yang ada di Jawa Barat. Pada langkah ini siswa lebih cenderung pada konsep kembali ke alam, kembali ke lingkungan untuk melihat kembali, bertanya kembali konteks-kontek seni yang ada di masyarakat. Mereka disuguhkan dengan pertunjukan bentuk-bentuk permaiann tradisional yang ada di Jawa Barat, seperti oray-orayan, endogendogan, cingciripit, endog-endogan, hompimpah, ucang-ucang angge, sasalimpetan dan bertanya kembali pada ahli. Kegiatan ini dinamakan dengan fase re-visiting dan re-questioning (Supriyanto, 2018, hlm. 102) atau fase knowing history (McCutchen, 2006, hlm. 254). Kegiatan ini penting dilakukan oleh siswa untuk mengetahui akar dari koreografi yang akan dikembangkan. Konsep ini sering dilakukan ketika koreografer akan memulai proses penciptaan tari, atau disebut juga dengan konsep observation (Lavender, 1996, hlm. 78). Pada pertemuan I peneliti melaksanakan pembelajaran untuk meningkatkan kompetensi penciptaan tari anak pada siswa dengan aspek kompetensi Elemen Dasar Tari, yaitu: konsep tubuh (body), konsep aksi (action), konsep ruang (space), konsep waktu (time), konsep tenaga (energy).

Nilai silih asih terdapat dalam perilaku empati ketika mengeksplorasi bentuk permainan anak dengan saling membantu, kemampuan berdisiplin ditunjukkan dengan cara belajar tepat waktu dan bersungguh-sungguh, bersabar ketika teman-temannya masih belum menemukan permainan anak, mengorbankan waktunya di luar pelajaran untuk tetap berlatih, saling menghormati dengan kelompok lainnya dengan cara tidak saling mengganggu. Nilai silih asah terdapat dalam perilaku bersemangat dalam berlatih, kejujuran dalam memberikan jawaban pada sesi tanya jawab, kreativitas yang ditunjukkan dengan menemukan bentuk permainan anak yang mempunyai lagu dan gerak, mampu berkomunikasi dengan temannya untuk menemukan bentuk permainan anak, mampu bersinergi dalam kelompoknya yang solid. Nilai asuh terdapat dalam saling menghargai dengan teman kelompoknya dengan cara tidak saling memaksakan kehendak, mampu mempunyai sikap ikhlas dalam menerima keputusan kelompok, mampu berbuat legowo ketika saran dan masukan tidak diterima kelompoknya, mampu menjalin kebersamaan dan kekompakan dalam mengerjakan tugas.

Pertemuan kedua adalah siswa mampu memilih bentuk-bentuk permainan anak untuk dijadikan sumber pengembangan koreografi dan dan pengetahuan aspek-aspek dasar komposisi kelompok yang meliputi: koreografi serempak (unison), koreografi sama dengan beda tempo (canon), koreografi saling mengisi (alternate), koreografi terpecah (broken), koreografi berimbang (balance). Pertemuan ini lebih menekankan pada kompetensi pemahaman teori yang terdapat dalam kekaryaan tari. Konsep ini adalah penjelajahan atau pendalaman terhadap elemen dasar tari, prinsip-prinsip bentuk seni tari, komposisi tari kelompok dan desain lantai. Fase kedua ini siswa harus memahami dengan teori-teori 
koreografi tari yang akan dijadikan sebagai ilmu untuk mengembangkan koreografi permainan anak sesuai dengan keilmuan koreografi tari. Nilai silih asih terdapat dalam perilaku empati ketika siswa saling membantu dalam mengeksplorasi aspek dasar tari kelompok gerak unison, canon, broken, alternate dan balance. Siswa mampu berdisiplin ditunjukkan dengan cara belajar tepat waktu dan bersungguh-sungguh, mampu bersabar ketika teman-temannya masih belum bisa mengeksplorasi gerak dasar tari kelompok, mengorbankan pemikiran dan tenaganya untuk berlatih gerak dasar tari kelompok, sikap saling menghormati sesama kelompoknya dalam mempelajari gerak dasar tari kelompok dengan cara saling mendukung dan tidak mengganggu.

Nilai silih asah terdapat dalam perilaku bersemangat dalam berlatih dasar tari kelompok, kejujuran dalam memberikan jawaban pada sesi tanya jawab, kreativitas yang ditunjukkan dengan menemukan contoh gerak baru dalam dasar tari kelompok, mampu berkomunikasi dengan temannya untuk bereksplorasi gerak tari kelompok, mampu bersinergi dalam menemukan gerak dasar tari kelompok. Nilai silih asuh terdapat dalam saling menghargai dengan teman kelompoknya dengan cara tidak saling memaksakan kehendak ketika menemukan gerak baru, mampu mempunyai sikap ikhlas dalam menerima keputusan kelompok pada proses penentuan gerak akhir tari kelompok, mampu berbuat ikhlas ketika gerak yang diciptakan tidak diterima kelompoknya, mampu menjalin kebersamaan dan kekompakan dalam mengerjakan tugas dilihat dari kekompakan dalam penyajian koreografi tari kelompok.

Pertemuan ketiga adalah siswa mampu membuat tema tari. Adapun materinya adalah tema tari yang terdiri dari tema tari yang meliputi tema lingkungan, heroik, mimitis, dan imitatif (Sunaryo, 2020b), adapun tema yang dipilih adalah tema mengenai lingkungan. Pada tahap ini siswa ditugaskan untuk membuat tema lingkungan, karena konteks permainan anak adalah tentang lingkungan agar siswa bisa mengenal diri, lingkungan dan Tuhannya (Alif, Sachari, \& Sabana, 2015). Tema pada tari dibuat struktur dramatiknya untuk memberikan alur ceritera pada koreografi secara utuh. Pada proses pembelajaran terdapat nilai silih asih terdapat dalam perilaku empati ketika siswa saling membantu dalam membuat tema tari. Siswa mampu berdisiplin ditunjukkan dengan cara belajar tepat waktu, siswa mampu bersabar ketika teman-temannya masih belum selesai membuat tema tari, mengorbankan pemikiran dan tenaganya untuk membuat tema tari, sikap saling menghormati sesama kelompoknya dengan cara saling mendukung dan tidak mengganggu. Nilai silih asah terdapat dalam perilaku bersemangat dalam membuat tema tari, kejujuran dalam memberikan jawaban pada sesi tanya jawab mengenai sumber tema tari, kreativitas yang ditunjukkan dengan menciptakan struktur dramatik baru, mampu berkomunikasi dengan temannya untuk membuat struktur dramatik. Nilai silih asuh terdapat dalam saling menghargai dengan teman kelompoknya dengan cara tidak saling memaksakan kehendak ketika menyusun struktur dramatik pada alur tema tari, mampu bersikap ikhlas dalam menerima keputusan kelompok, mampu berbuat ikhlas ketika alur ceritera tidak dipakai, mampu menjalin kebersamaan dan kekompakan dalam mengerjakan tugas pembuatan struktur dramatik pada alur tema tari.

Pertemuan keempat adalah siswa mampu memahami dan terampil mengenai pengembangan koreografi permainan anak serta eksplorasi, improvisasi dan pembentukan. Koreografi yang sudah baku dari permainan anak dikembangkan tetapi tidak menghilangkan unsur aslinya. Konsep koreografi yang berasal dari permainan anak sehingga dalam pelaksanaannya lebih fokus pada aspek eksplorasi, improvisasi dan pembentukan (Hawkins, 1964) atau fase develoving skill (Gilbert, 2002). Implikasi dari improvisasi adalah tidak pernah dapat diulangi, kecuali secara kebetulan (Carter, 2000). Improvisasi juga menunjukan hubungan antara domain motorik, kognitif dan emotif (Biasutti, 2013). Usia siswa merupakan isu signifikan dalam pembelajaran tari, baik terkait dengan isi materi maupun pendekatan pengajarannya berdasarkan tingkat perkembangan kemampuan dan pemahamannya (Masunah: 2011). 
Anak-anak memiliki pendekatan belajar yang komprehensif (Lindqvist, 2001). Nilai silih asih terdapat dalam perilaku empati ketika siswa saling membantu dalam mengeksplorasi. Siswa mampu berdisiplin ditunjukkan dengan cara belajar tepat waktu dan bersungguh-sungguh, mampu bersabar ketika teman-temannya masih belum bisa mengeksplorasi dan improvisasi, mengorbankan pemikiran dan tenaganya untuk berlatih pengembangan koreografi permainan anak, sikap saling menghormati sesama kelompoknya dalam mempelajari pengembangan koreografi dengan cara tidak saling mendukung dan mengganggu. Nilai silih asah terdapat dalam perilaku bersemangat dalam bereksplorasi dan improvisasi koreografi permainan anak, kejujuran dalam memberikan jawaban pada sesi tanya jawab mengenai improvisasi perubahan gerak asli, kreativitas yang ditunjukkan dengan menemukan contoh gerak baru dalam improvisasi koreografi, mampu berkomunikasi dengan temannya untuk bereksplorasi koreografi baru, mampu bersinergi dalam menemukan gerak baru pada eksplorasi dan improvisasi koreografi permainan anak. Nilai silih asuh terdapat dalam saling menghargai dengan teman kelompoknya dengan cara tidak saling memaksakan kehendak ketika sudah menemukan gerak baru dan tidak dipakai, mampu mempunyai sikap ikhlas dalam menerima keputusan kelompok pada proses pembentukan pengembangan koreografi tari anak, mampu berbuat ikhlas ketika koreografi yang diciptakan tidak masuk terhadap pembentukan koreografi, mampu menjalin kebersamaan dan kekompakan dalam mengerjakan tugas dilihat dari kekompakan dalam proses eksplorasi dan improvisasi.

Pertemuan kelima adalah siswa mampu melakukan pembentukan koreografi secara permanen sesuai dengan kebutuhan struktur dramatik. Adapun materinya adalah pengembangan koreografi yang berbasis permainan anak dan struktur dran guru. Pertemuan ini lebih menekankan pada presentasi karya komposisi tari anak yang ditarikan oleh orang dewasa yang dilakukan secara kelompok. Konsep Locking and presenting adalah kegiatan mengunci atau membakukan koreografi tari anak yang dibuat oleh siswa dan dipresentasikan oleh siswa. Konsep ini disebut dengan konsep pembentukan (Hawkins, 2003, hlm. 87). Nilai silih asih terdapat dalam perilaku empati ketika siswa saling membantu dalam membentuk pengembangan koreografi permainan anak secara utuh. Siswa mampu berdisiplin ditunjukkan dengan cara belajar tepat waktu dan bersungguh-sungguh, mampu bersabar ketika teman-temannya masih belum bisa membentuk dengan sempurna pengembangan gerak permainan anak secara utuh, mengorbankan pemikiran dan tenaganya untuk berlatih membentuk pengembangan koreografi permainan anak secara utuh, sikap saling menghormati sesama kelompoknya dalam membentuk koreografi permainan anak secara utuh dengan cara saling mendukung dan tidak mengganggu.

Nilai silih asah terdapat dalam perilaku bersemangat dalam membentuk koreografi permainan anak secara utuh, kejujuran dalam memberikan jawaban pada sesi tanya jawab mengenai perubahan gerak asli dalam pembentukan koreografi permainan anak secara utuh, kreativitas yang ditunjukkan dengan menemukan contoh gerak baru dalam hasil pembentukan koreografi baru secara utuh, mampu berkomunikasi dengan temannya untuk membentuk koreografi baru yang bersumber dari permainan anak secara utuh, mampu bersinergi dalam membentuk koreografi permainan anak secara utuh. Nilai silih asuh terdapat dalam saling menghargai dengan teman kelompoknya dengan cara tidak saling memaksakan kehendak ketika akan membentuk tahap akhir koreografi secara utuh, mampu mempunyai sikap ikhlas dalam menerima keputusan kelompok pada proses pembentukan koreografi tari anak secara utuh, mampu berbuat ikhlas ketika koreografi yang diciptakan tidak masuk terhadap pembentukan koreografi secara utuh, mampu menjalin kebersamaan dan kekompakan dalam mengerjakan tugas dilihat dari kekompakan dalam penyajian pembentukan akhir pengembangan koreografi permainan anak secara utuh.

Pertemuan keenam adalah adalah siswa mampu melakukan evaluasi terhadap koreografi tari anak berbasis permainan anak. Adapun materinya adalah tentang nilai-nilai kearifan lokal Sunda yang disebut dengan Tri-Silas. Pertemuan ini lebih menekankan pada 
evaluasi tentang teknik koreografi, pengembangan koreografi, struktur dramatik dan nilai yang terkandung dalam setiap karya yang dipresentasikan. Konsep Evaluation yaitu kegiatan evaluasi atau revisi ketika karya koreografi tari anak dipresentasikan (Lavender, 2006, hlm. 96). Nilai silih asih terdapat dalam koreografi dengan relationship yaitu gerak yang saling berhubungan antara satu siswa dengan siswa lainnya atau kelompoknya. Nilai silih asah terdapat dalam koreografi unison, alternate, balance, broken, canon pada permainan anak dengan karakter koreografi yang saling menarik (mutually attractive motion), saling mendorong (push) dan gerak yang memberikan efek non balance atau ketidak seimbangan pada tubuh. Nilai asuh terdapat dalam koreografi saling menjaga keseimbangan tubuh agar tidak jatuh, gerak yang menjaga formasi kelompok (leap, run, walk, jump, gallop) agar tetap pada porosnya.

Adapun hasil penciptaan karya tari salah satu kelompok, yaitu sebagai berikut.

Kelompok 1 Judul "Arulin" (Bermain)

Sinopsis:

Awal ceritera menceriterakan seorang anak yang mencari temannya untuk bermain di halaman rumah, kemudian beberapa anak-anak berdatangan dan ikut bermain. Permainan yang dilakukan adalah oray-orayan, tokecang, slepdur, sasalimpetan dan cingciripit, mereka bermain dan bergembira Ketika bermain salah satu anak terpeleset karena di dorong oleh temannya dan marah, lalu menangis Terjadilah cekcok tetapi kemudian mereka damai bahwa manusia harus hidup bersama dengan damai kemudian mereka bermain kembali Kemudian mereka pulang ke rumahnya masing-masing karena hari sudah senja. Kemudian mereka menunaikan shalat magrib berjamaah di masigit.

\begin{tabular}{|c|c|c|c|c|c|c|c|c|c|c|c|c|c|c|c|}
\hline \multicolumn{10}{|c|}{ PENGEMBANGAN ELEMEN DASAR TARI (BASTE) } & \multirow{2}{*}{\multicolumn{3}{|c|}{ PENGEMBANGAN KOREOGRAFI }} & \multirow[b]{2}{*}{$\begin{array}{l}\text { PENGEMBANGAN } \\
\text { RELATIONSHIP }\end{array}$} & \multirow{2}{*}{\multicolumn{2}{|c|}{$\begin{array}{c}\text { PENGEMBANGAN } \\
\text { DESAIN LANTAI } \\
\text { POLA GARIS } \\
\text { (PATERN) }\end{array}$}} \\
\hline BODY & \multicolumn{2}{|c|}{ ACTION } & \multicolumn{2}{|c|}{ SPACE } & \multicolumn{2}{|l|}{ TIME } & \multicolumn{3}{|c|}{ ENERGY } & & & & & & \\
\hline $\begin{array}{l}\text { Kepala (head) } \\
\text { Statonary } \\
\text { Swinging } \\
\text { Jumping } \\
\text { Giggling } \\
\text { shake }\end{array}$ & \multirow{4}{*}{\multicolumn{2}{|c|}{$\begin{array}{l}\text { Berjalan (walk) } \\
\text { Berlari } \\
\text { (run) } \\
\text { Meloncat (leap) } \\
\text { Berjingkat (hop) } \\
\text { Meloncat (jump) } \\
\text { Berlari } \\
\text { (gallop) } \\
\text { Membengkokan } \\
\text { (bend) } \\
\text { Meregang (strvtch) } \\
\text { Menarik (pull) } \\
\text { Menekan (push) } \\
\text { Mengangkat (lift) } \\
\text { Memutas (twist) } \\
\text { Berputar-putar } \\
\text { (twirlling) } \\
\text { Berguling } \\
\text { (rolling) } \\
\text { Jatuh } \\
\text { (fall) }\end{array}$}} & \multirow{4}{*}{\multicolumn{2}{|c|}{ 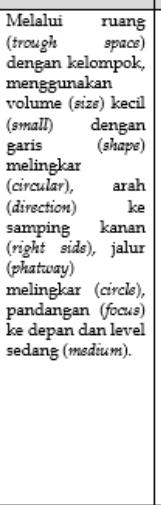 }} & \multirow{4}{*}{\multicolumn{2}{|c|}{$\begin{array}{l}\text { Tenaga berat } \\
\text { (heavy), } \\
\text { tegang } \\
\text { (tenssd), } \\
\text { ketat (tight), } \\
\text { mengikat } \\
\text { (bound) } \\
\text { ketika loncat } \\
\text { (jumping) }\end{array}$}} & \multirow{4}{*}{\multicolumn{3}{|c|}{\begin{tabular}{|l|} 
Tempo(tsmpo) \\
yang digunakan \\
adalah sedang \\
(medium) dengan \\
bit (bsat) tetap dan \\
durasi (duration) \\
berkelanjutan \\
(sustained). \\
prasing \\
dilakukang secara \\
serempak dengan \\
pola (pattern) \\
berurutan, \\
(sequencs)
\end{tabular}}} & & & & \multirow{4}{*}{$\begin{array}{l}\text { Kali (leg) berselang } \\
\text { seling dan } \\
\text { menyentuh (touch) } \\
\text { dengan cara } \\
\text { menganyam } \\
\text { (wasaving) dengan } \\
\text { pemain lainnya. } \\
\text { (body part to group. } \\
\text { Tangan menyentuh } \\
\text { pingeang dan } \\
\text { pundak, } \\
\text { Badan bersentuhan } \\
\text { dengan badan }\end{array}$} & \multirow{4}{*}{\begin{tabular}{|l} 
Desain \\
lantai \\
melingk \\
ar ke \\
arah \\
kanan \\
seperti \\
lingkara \\
n (circle), \\
dengan \\
konsep \\
idsr naga.
\end{tabular}} & \\
\hline $\begin{array}{l}\text { Badan (torso) } \\
\text { Crawl } \\
\text { Fall } \\
\text { Riss } \\
\text { Melt } \\
\text { Twist } \\
\text { Twirling }\end{array}$ & & & & & & & & & & & & & & & \\
\hline $\begin{array}{l}\text { Tangan (arm) } \\
\text { Bond } \\
\text { Strvtch } \\
\text { swing }\end{array}$ & & & & & & & & & & & & & & & \\
\hline $\begin{array}{l}\text { Kaki }(\mathrm{lgg}) \\
\text { Leap } \\
\text { Jump } \\
\text { Hop } \\
\text { Gallop } \\
\text { Slids } \\
\text { walk }\end{array}$ & & & & & & & & & & & & & & & \\
\hline \multicolumn{5}{|c|}{ BASIC ASPECTS OF GROUP COREOGRAPHY } & \multicolumn{3}{|c|}{ LINE DESAIN } & \multicolumn{3}{|c|}{$\begin{array}{c}\text { BODY } \\
\text { CONSTRUCTION } \\
\text { CONTROLS }\end{array}$} & \multirow[t]{2}{*}{$\begin{array}{l}\text { TEMA/ } \\
\text { JUDUR }\end{array}$} & & \multirow{2}{*}{\multicolumn{2}{|c|}{$\begin{array}{l}\text { NIIAI } \\
\text { SILAS }\end{array}$}} & \\
\hline unison & caros & $\begin{array}{l}\text { ATEREN } \\
\text { ATE }\end{array}$ & $\underset{N}{\text { BROKE }}$ & $\begin{array}{c}\text { BALAN } \\
\text { CE }\end{array}$ & $\begin{array}{l}\text { SIME } \\
\text { TRIS }\end{array}$ & & $\begin{array}{l}\text { SIME } \\
\text { IRIS }\end{array}$ & $\begin{array}{l}\text { STAT } \\
\text { IONA }\end{array}$ & & $\begin{array}{l}\text { COMOT } \\
\text { OR }\end{array}$ & & STRUKTUR DRAMATIK & & & \\
\hline $\begin{array}{l}\text { Komposisi } \\
\text { kelompok } \\
\text { dilakukan } \\
\text { secara } \\
\text { unison } \\
\text { (serempak) } \\
\text { dengan } \\
\text { cara } \\
\text { berjalan ke } \\
\text { depan. }\end{array}$ & $\begin{array}{c}\text { Ketika } \\
\text { gerak } \\
\text { pada } \\
\text { pengem } \\
\text { bangan } \\
\text { sasalim } \\
\text { petan } \\
\text { mengg } \\
\text { unakan } \\
\text { pola } \\
\text { canon }\end{array}$ & $\begin{array}{l}\text { Komposisi } \\
\text { kelompok } \\
\text { saling } \\
\text { mengisi } \\
\text { (altermats) } \\
\text { terdapat } \\
\text { dalam } \\
\text { gerak } \\
\text { menganya } \\
\text { m } \\
\text { (usarving) } \\
\text { kaki (logg). }\end{array}$ & $\begin{array}{l}\text { Koreogr } \\
\text { afi } \\
\text { memeca } \\
\text { h ketika } \\
\text { anak- } \\
\text { anak } \\
\text { berdatan } \\
\text { gan dari } \\
\text { empat } \\
\text { penjuru }\end{array}$ & $\begin{array}{l}\text { Koreogr } \\
\text { afi } \\
\text { seimban } \\
\mathrm{g} \text { pada } \\
\text { saat } \\
\text { bersala } \\
\text { man }\end{array}$ & 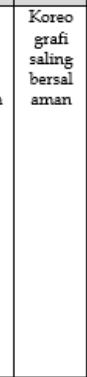 & & $\begin{array}{l}\text { sisi } \\
\text { ki } \\
\text { angga } \\
\text { satu } \\
\text { n } \\
\text { sain } \\
\text { trai } \\
\text { ris } \\
\text { lingk } \\
\text { (circls) }\end{array}$ & $\begin{array}{c}\text { Koreo } \\
\text { grafi } \\
\text { diam } \\
\text { ditem } \\
\text { mpat } \\
\text { pada } \\
\text { saat } \\
\text { menu } \\
\text { nggu } \\
\text { teman } \\
-- \\
\text { teman } \\
\text { nya }\end{array}$ & & $\begin{array}{l}\text { rak } \\
\text { rpindah } \\
\text { dapat } \\
\text { da } \\
\text { mposisi } \\
\text { lompok } \\
\text { ng sedang } \\
\text { ccat } \\
\text { mping) } \\
\text { inggunak } \\
\text { satu kaki } \\
\text { g). }\end{array}$ & Arulin & 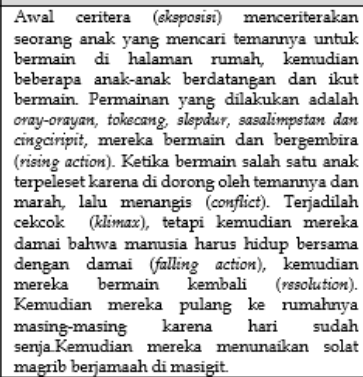 & \begin{tabular}{l|l} 
an & \\
ik & 1. Religius \\
an & 2. Jujur \\
ut & 3. Toleransi \\
ah & 4. Disiplin \\
an & 5. Keja keras \\
ra & 6. Kreatif \\
ak & 7. Mandiri \\
an & 8. Demokratis \\
ah & 9. Semangat \\
ka & 10. Cinta tanah air \\
at & 11. Bersahabat/ ko \\
an & 12. Cinta Damai \\
i). & 13. Peduli Lingku \\
ya & 14. Peduli sosial \\
ha & 15. Tanggung Jaw \\
at &
\end{tabular} & $\begin{array}{l}\text { omunikatif } \\
\text { ngan } \\
\text { ab }\end{array}$ & \\
\hline
\end{tabular}

\section{Gambar 3. Analisis Koreografi}

Pada gambar 3, dijelaskan mengenai analisis koreografi tari anak yang berjudul "Arulin" (Bermain) yang dilakukan oleh salah satu kelompok siswa. Analisisnya meliputu elemen dasar tari dengan pola BASTE (body, action, space, time, energy), analisa koreografinya yang menegembangkan dari pola-pola gerak yang baku permainan anak, pengembangan desain lantai (patern) yang mengalami pengembangan pada bentuk garis diagonal, horizontal, 
Information \& Communication Technology in Building Children Character During the Covid-19 Pandemic DOI: 10.31004/obsesi.v5i2.594

setengah lingkaran dan angka delapan. Adapun bentuk tari kelompok dianalisis dengan aspek dasar tari kelompok yang meliputi: simultan, canon, alternate, balance, broken. Alur ceritera dalam struktur dramatik dianalisis menggunakan teori Freintag yang terdiri dari eksplanasi, ricing action, conflic, climax, resolusi dan conclution, sedangkan nilai Tri-Silas merupakan nilai-nilai yang terdapat dalam alur ceritera.

Tabel 3 dan 4 serta gambar 2 menunjukkan efektivitas pembelajaran tari anak dalam menginternalisasi nilai Tri-Silas berbasis budaya lokal

Tabel 3. Frekuensi Nilai Pre tes Sebelum Penerapan Pembelajaran

\begin{tabular}{|c|c|c|c|c|c|}
\hline & & Frequency & Percent & Valid Percent & Cumulative Percent \\
\hline \multirow{5}{*}{ Valid } & 62 & 3 & 10.0 & 10.0 & 10.0 \\
\hline & 63 & 19 & 63.3 & 63.3 & 73.3 \\
\hline & 64 & 7 & 23.3 & 23.3 & 96.7 \\
\hline & 65 & 1 & 3.3 & 3.3 & 100.0 \\
\hline & Total & 30 & 100.0 & 100.0 & \\
\hline
\end{tabular}

Tabel 4. Frekuensi Nilai Post test Sesudah Penerapan Pembelajaran

\begin{tabular}{|c|c|c|c|c|c|}
\hline & & Frequency & Percent & Valid Percent & Cumulative Percent \\
\hline \multirow{3}{*}{ Valid } & 95 & 13 & 43.3 & 43.3 & 43.3 \\
\hline & 96 & 17 & 56.7 & 56.7 & 100.0 \\
\hline & Total & 30 & 100.0 & 100.0 & \\
\hline
\end{tabular}
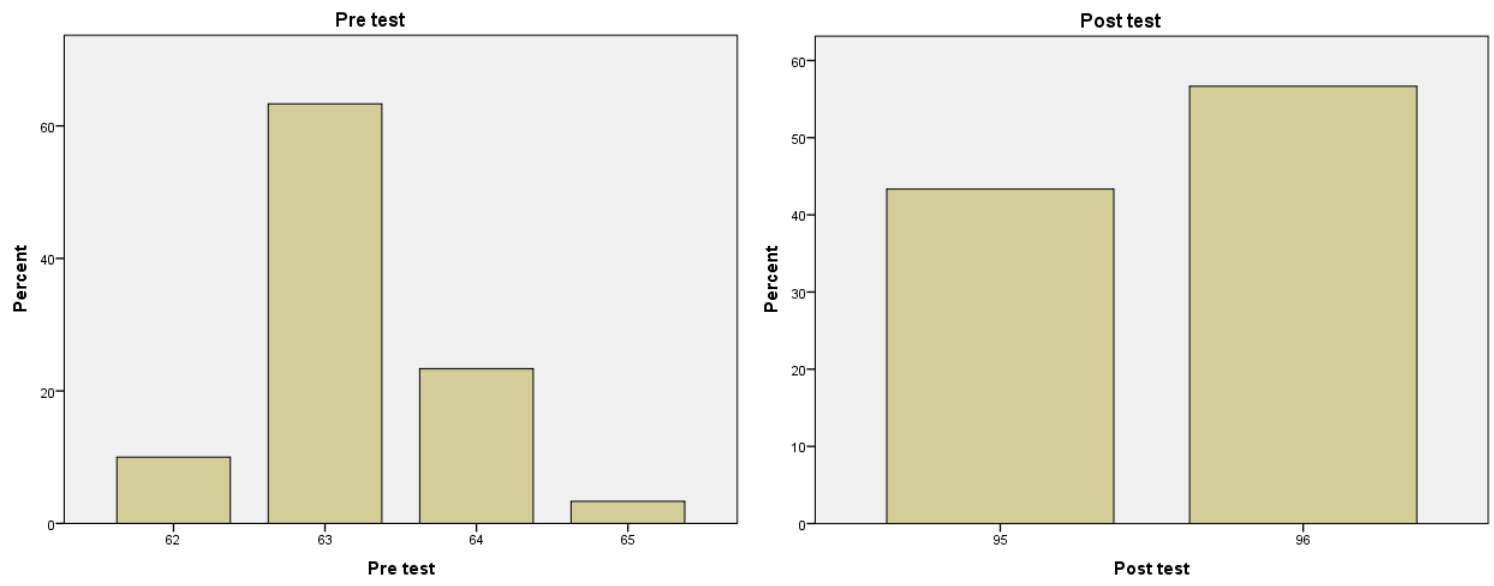

Gambar 2. Hasil Uji Pre Test dan Post Test

Uji statistik yang digunakan dalam penelitian ini adalah uji statistik non parametrik, atas dasar Uji Normalitas yang menunjukan distribusi data yang tidak normal. Untuk mengetahui efektivitas antara pre test dan post test yang telah dilaksanakan dalam penerapan model ini, peneliti menggunakan Uji Wilcoxon, karena data termasuk pada non parametrik. Uji Wilcoxon digunakan sebagai alternatif dari uji paired sample $t$ test, jika data penelitian tidak berdistribusi normal.

Tabel 5. Ranks

\begin{tabular}{|ll|r|r|r|}
\hline & N & Mean Rank & Sum of Ranks \\
\hline & Negative Ranks & $0^{\mathrm{a}}$ & .00 & .00 \\
Post test - Pre test & $52^{\mathrm{b}}$ & 26.50 & 1378.00 \\
& Positive Ranks & $0^{\mathrm{c}}$ & & \\
& Ties & 52 & & \\
& Total & & \\
\hline
\end{tabular}


Tabel 6. Test Statistics ${ }^{a}$

\begin{tabular}{|l|r|}
\hline & Post test - Pre test \\
\hline$Z$ & $-6.404^{\mathrm{b}}$ \\
$\begin{array}{l}\text { Asymp. Sig. (2- } \\
\text { tailed) }\end{array}$ & .000 \\
\hline
\end{tabular}

a. Wilcoxon Signed Ranks Test

b. Based on negative ranks.

Berdasarkan tabel uji tersebut diatas, diperoleh output berikut: Negative Ranks atau selisih (negatif) antara hasil belajar untuk pre test dan pos test adalah 0 , baik itu pada nilai N, Mean Rank, maupun Sum Rank. Nilai 0 ini menunjukan tidak adanya penurunan (pengurangan) dari nilai Pre Test ke nilai Pos test. Positif Ranks atau selisih (positif) antara hasil belajar untuk pre test dan pos test. Disini terdapat 52 data positif $(\mathrm{N})$ yang artinya ke 52 peserta mengalami peningkatan hasil belajar dari nilai pre test ke nilai post test. Mean Rank atau rata-rata peningkatan tersebut adalah 26,50, sedangkan jumlah ranking positif atau Sum of Ranks adalah sebesar 1378,00. Ties adalah kesamaan nilai Pre test dan Post test, disini nilai Ties adalah 0 , sehingga dapat dikatakan bahwa tidak ada nilai yang sama antara pre test dan post test. Pengambilan keputusan berdasarkan output "Test Statistics", diketahui Asymp.Sig (2-tailed) bernilai 0,000. Karena nilai 0,000 lebih kecil dari <0,05, maka dapat disimpulkan "Hipotesis diterima".

\section{SIMPULAN}

Tahap-tahap ini disusun sebagai strategi mencapai tujuan pembelajaran untuk menginternalisasi nilai Tri-Silas pada siswa. Guru membantu siswa membimbing dalam proses secara intelektual dan mental. Siswa memiliki kebebasan dalam diskusi, bekerjasama, dan berproses kreatif. Peran guru disini sangat penting dalam mengembangkan dan mendorong kreativitas siswa. Dari keseluruhan karya yang ditampilkan dapat terlihat pengembangan dari koreografi yang sudah ada, dan terobservasi sikap silih asih, silih asih, silih asuh antar siswa dan guru dengan saling bergotong royong, bersemangat, jujur, ikhlas, berani dan berempati. Permainan tradisional anak merupakan salah satu solusi untuk dapat mengenalkan siswa pada budaya lokal sekalis menginternalisasi nilai-nilainya pada diri siswa.

\section{UCAPAN TERIMAKASIH}

Terimakasih kami ucapkan kepada semua pihak yang berperan dalam proses penelitian ini. Terutama kepada Ketua Departemen dan civitas akademika Pascasarjana UPI dan YAS Bandung. Juga, kepada tiga orang Profesor pembimbing. Ucapan terima kasih juga disampaikan kepada tim editor Jurnal Obsesi yang telah memberikan saran, kritik, dan rekomendasi untuk perbaikan artikel ini.

\section{DAFTAR PUSTAKA}

Alif, M. Z., Sachari, A., \& Sabana, S. (2015). Konsep Desain Venakular Dalam Bentuk pagawéan barudak di Baduy-Dalam. Panggung, 25(4), 391-404. https:// doi.org/10.26742/panggung.v25i4.46

Biasutti, M. (2013). Improvisation in dance education: teacher views. Research in Dance Education, 14(2), 120-140. https://doi.org/10.1080/14647893.2012.761193

Carter, C. L. (2000). Improvisation in Dance. The Journal of Aesthetics and Art Criticism, 58(2), 181. https:// doi.org/10.2307/ 432097

Danasasmita, S. (1987). Sanghyang Siksa Kandang Karesian.-Amanat Galunggung. Departemen Pendidikan dan Kebudayaan. 
Davis, M. (2003). What's Wrong with Character Education? American Journal of Education, 1(11), 32-57. https://doi.org/10.1086/377672

Djunatan, S. (2011). Silih Asah, Silih Asih, Silih Asuh: Inspirasi Budaya Lokal Untuk Gereja. Jurnal Studia Philosophica et Theologica, 11 No. 1(Maret), 115-127.

Giguere, M. (2006). Thinking as They Create: Do Children have Similar Experiences in Dance and in Language Arts? Journal of Dance Education, 6(2), 41-47. https://doi.org/10.1080/15290824.2006.10387311

Giguere, M. (2011). Dances for Children, with Children, and by Children: Looking at Recital Dance through a Lens of Children's Culture. Journal of Dance Education, 11(3), 84-89. https://doi.org/10.1080/15290824.2011.564077

Gilbert, A. G. (2002). Creative Dance for All Ages (Second Edi). Champaign United States: Human Kinetics.

Hawkins, A. (2003). Moving form Within: A New Method for Dance Making. Bergerak Menurut Kata Hati. Terjemahan oleh I Wayan Dibya. Jakarta: MSPI.

Hawkins, A. M. (1965). Creating through dance. UCLA: Prentice-Hall.

Kartadinata, S. (2010). Mencari Bentuk Pendidikan Karakter Bangsa. Bandung: UPI Press.

Krakowiak, K. M., \& Tsay-Vogel, M. (2013). What Makes Characters' Bad Behaviors Acceptable? The Effects of Character Motivation and Outcome on Perceptions, Character Liking, and Moral Disengagement. Mass Communication and Society, 16(2), 179-199. https:// doi.org/10.1080/15205436.2012.690926

Kuswarsantyo. (2012). Pelajaran Tari: Image dan Kontribusinya Terhadap Pembentukan Karakter Anak. JOGED Jurnal Seni Tari, 3(1), 17-23. https://doi.org/https://doi.org/10.15294/jst.v4i1.9642

Lavender, L. (1996). Dancers Talking Dance: Critical Evaluation in the Choreography Class. Human Kinetics.

Lavender, L. (2006). Creative Process Mentoring: Teaching the "Making" in Dance-Making. Journal of Dance Education, 6(1), 6-13. https:/ / doi.org/10.1080/15290824.2006.10387306

Lindqvist, G. (2001). The Relationship between Play and Dance. Research in Dance Education, 2(1), 41-52. https:// doi.org/10.1080/14647890120058302

Malarsih, \& Herlinah. (2014). Creativity Education Model through Dance Creation for Students of Junior High School. Harmonia: Journal of Arts Research and Education, 14(2), 147. https:// doi.org/10.15294/harmonia.v14i2.3296

Masunah, J. (2011). Konsep Dan Praktik Pendidikan Multikultural Di Amerika Serikat dan Indonesia. Jurnal Ilmu Pendidikan, vol 17.

McCutchen, B. P. (2006). Teaching Dance as Art in Education. Champaign. United Sates: Human Kinetics.

Novianti, N. (2017). Teaching character education to college students using bildungsromans. International Journal of Instruction, 10(4), 255-272. https://doi.org/10.12973/iji.2017.10415a

Noviati, P. R., \& Giwangsa, S. F. (2018). Analisis Permainan Oray-Orayan Terhadap Aspek Perkembangan Anak Analysis of Orayan-Orayan Games on Children ' S. JURNAL LENSA PENDAS, 3(September), 73-78.

Nurwansah, I. (2013). Naskah Lontar Sunda Kuna Sanghyang Siksa Kandang Karesian (624): Sebuah anomali pada pernaskahan Sunda Kuna. Jurnal Jumantara, 4(1). Retrieved from file:///C:/Users/Asus-

User/Downloads/Naskah_Lontar_Sunda_Kuna_Sanghyang_Siksa.pdfnda Kuna

Rakimahwati. (2014). Character Development through Dance Learning in an Early Childhood Setting. Indonesian Journal of Early Childhood Education Studies, 3(2), 102-107. https://doi.org/10.15294/ijeces.v3i2.9490

Sudaryat, Y. (2016). Bahasa Sunda Dalam Gamitan Kearifan Lokal Dan Pendidikan. Retrieved from http:// berita.upi.edu/11149/

Sunaryo, A. (2020a). Dasar-Dasar Koreografi (1st ed.). Bandung: UPI Press. 
Sunaryo, A. (2020b). Pengembangan Model ENGKLE Berbasis Permainan Tradisi Untuk Meningkatkan Kompetensi Penciptaan Tari Anak. Sekolah Pascasarjana Universitas Pendidikan Indonesia.

Sunaryo, A., Narawati, T., Masunah, J., \& Nugraheni, T. (2020). Concept of Children's Dance Composition Based Traditional Games in Elementary School. Jurnal Pendidikan Sekolah Dasar, 6(1).

Sundalana. (2006). Mencari Gerbang Pakuan dan Kajian Lainnya mengenai Budaya Sunda. Bandung: Pusat Studi Sunda.

Supriyanto, E. (2018). Ikat Kait Impulsif Sarira: Gagasan Yang Mewujud Era 1990-2010 (R. S. Wulan, Ed.). Yogyakarta: Garudhawaca.

Suryalaga, R. H. (2010). Kesundaan Rawayan Jati. Bandung: Yayasan Nur Hidayah.

Yani, A., \& Jazariyah, J. (2020). Penyelenggaraan PAUD Berbasis Karakter Kebhinekaan sebagai Upaya Pencegahan Radikalisme Sejak Dini. Jurnal Obsesi : Jurnal Pendidikan Anak Usia Dini, 5(1), 1. https:/ / doi.org/10.31004/obsesi.v5i1.503 